\title{
LACUNAS CARTOGRÁFICAS NA DELIMITAÇÃO TERRITORIAL EM ÁREAS PROTEGIDAS
}

\section{CARTOGRAPHIC GAPS IN TERRITORIAL DELIMITATION ON PROTECTED AREAS}

\author{
Olavo Fagundes da Silva ${ }^{1}$ \\ http://orcid.org/0000-0001-8855-7396 \\ http://lattes.cnpq.br/4944584463093944
}

Recebido em: 30 de maio de 2020

Aprovado em: 31 de julho de 2020

RESUMO: As sobreposições territoriais constituem um dos problemas mais comuns para o processo de gestão territorial e ambiental das áreas protegidas no Brasil. Este trabalho faz a análise das sobreposições territoriais da área de manejo florestal do Grupo Jari, de iniciativa privada, na Reserva de Desenvolvimento Sustentável do Rio Iratapuru e no Projeto de Assentamento Agroextrativista do Rio Maracá, situados no sul do Amapá e suas implicações no processo de gestão territorial e ambiental. Com base em análise espacial de dados em Sistema de Informações Geográficas e pesquisa documental confeccionou-se o mapa das sobreposições territoriais existentes. A partir desse mapa calculou-se a extensão e localização das sobreposições territoriais e algumas implicações nas dinâmicas territoriais, sociais, econômicas e ambientais em função dos usos da terra.

Palavras-chave: Sobreposições territoriais. Áreas protegidas. Sul do Amapá

\begin{abstract}
Territorial overlays are one of the most common problems for the process of territorial and environmental management of protected areas in Brazil. This work analyzes the territorial overlaps of the forest management area of Grupo Jari, of private initiative, in the Rio Iratapuru Sustainable Development Reserve and in the Rio Maracá Agroextractive Settlement Project, located in the south of Amapá and its implications in the process of territorial and environmental management. Based on spatial analysis of data in the Geographic Information System and documentary research, a map of the existing territorial overlaps was made. From this map, the extent and location of territorial overlaps and some implications for territorial, social, economic and environmental dynamics were calculated based on land uses.
\end{abstract}

Keywords: Territorial overlays. Protected areas. South of Amapá

${ }^{1}$ Geógrafo, Mestre em Desenvolvimento Regional, Doutor em Geografia Física pela Universidade de Coimbra e Doutor em Desenvolvimento Socioambiental pela Universidade Federal do Pará, atuou como Coordenador de Desenvolvimento Tecnológico e Inovação na Secretaria de Ciência e Tecnologia do Estado do Amapá, Professor substituto na Universidade Federal do Amapá e Professor no Instituto Federal do Amapá. E-mail: olavofagundes@yahoo.com. 


\section{INTRODUÇÃO}

A abordagem sobre conflitos territoriais na Amazônia insere-se dentro de um debate amplo entre diversos agentes. Destacam-se nesse debate o Estado nacional brasileiro, a iniciativa privada, organizações não governamentais e eventuais representantes das comunidades direta ou indiretamente envolvidas. Embora tenham interesse nos resultados, os agentes internacionais agem, na maioria das vezes em segundo plano, como mediadores ou em alguns casos, como observadores. $\mathrm{Na}$ atualidade esse debate ganhou novos ares em função da mudança no viés político-ideológico nacional. Os conflitos territoriais e sobreposições territoriais foram inflados pela ótica do desenvolvimento a qualquer custo.

O desenvolvimento socioeconômico da Amazônia brasileira, entre o final da última década do século XX e início deste século oscilou entre dois modelos principais. O modelo tradicional, baseado na apropriação a qualquer custo e um modelo novo, baseado na apropriação menos impactante. Acerca desses diferentes modelos, Kohlhepp (2002) enuncia as diferentes fases dos recentes programas desenvolvimentistas na Amazônia brasileira. Consideradas as devidas diferenças, ambos os modelos apresentam diferentes facetas da apropriação capitalista onde o valor de troca sobrepõe-se sobre o valor de uso.

A prática de apropriação indébita de áreas florestadas tem sido fomentada através da expansão de atividades tradicionalmente de grande impacto negativo sobre a floresta (BARRETO et.al. 2005). Entre essas atividades a de retirada convencional e muitas vezes ilegal de madeira tem papel preponderante. É a partir desse tipo de apropriação que se inicia um formato de empreendimento nefasto cuja sequência em muitos casos é a posterior instalação de pecuária extensiva e no limite a implantação das lavouras de larga escala como a soja. Essa forma de apropriação há algum tempo vem se expandindo sobre a Amazônia meridional, onde os cenários de conservação são pouco animadores, tal como já anunciado nas projeções de Britaldo et.al. (2006).

$\mathrm{Na}$ atualidade, o incentivo velado para expansão da atividade garimpeira em áreas protegidas também constitui fator de gradativa fragilização na proteção das florestas e das comunidades tradicionais Amazônicas. Essas atividades, entretanto, são quase sempre levadas a cabo por grupos organizados em torno de iniciativas do grande capital, mas nunca diretamente por grandes empresas. Para além das questões mais imediatas como a posse legítima da terra para quem de direito, a apropriação e desmatamento na Amazônia implicam em alterações mais abrangentes, como na dinâmica climática. Os efeitos na circulação atmosférica produzidos pela apropriação indevida e inadequada da floresta amazônica já foram bastante estudados e documentados por Marengo et.al. (2011) e Fearnside (2008) para citar apenas dois dentre os inúmeros cientistas de renome que estudam o processo.

Um dos empreendimentos do Grupo empresarial Jari no extremo sul do estado do Amapá é um caso ímpar de iniciativa direta de apropriação de grande área florestada sob ótica desenvolvimentista nova. A principal finalidade do Projeto REDD+ Jari/Amapá é o manejo florestal certificado. Entretanto, de acordo com Ribeiro et.al.(2013) além do manejo da floresta nativa, o projeto visa também obter créditos de carbono através de Redução de Emissão por Desmatamento e Degradação (REDD) e pelos serviços ambientais da floresta preservada conforme preconizado por Parker et.al. (2009).

Embora o manejo florestal, principal atividade do Grupo Jari, seja importante para a apropriação menos degradante da floresta Amazônica em larga escala, os meios de aquisição da 
área para uso são questionáveis. Aproximadamente 30\% da extensão territorial total anunciada como de propriedade legítima do Grupo Jari estão sobrepostos sobre duas áreas protegidas. Não fosse a diferença de uso da floresta, a legitimação de propriedade seguiria os mesmos princípios da apropriação para uso em outros cantos da imensa Amazônia brasileira.

A área deste estudo está localizada no sul do Amapá e abrange os municípios de Laranjal do Jari, Vitória do Jari e Mazagão (Figura1).

Figura 1: Localização da área de estudo

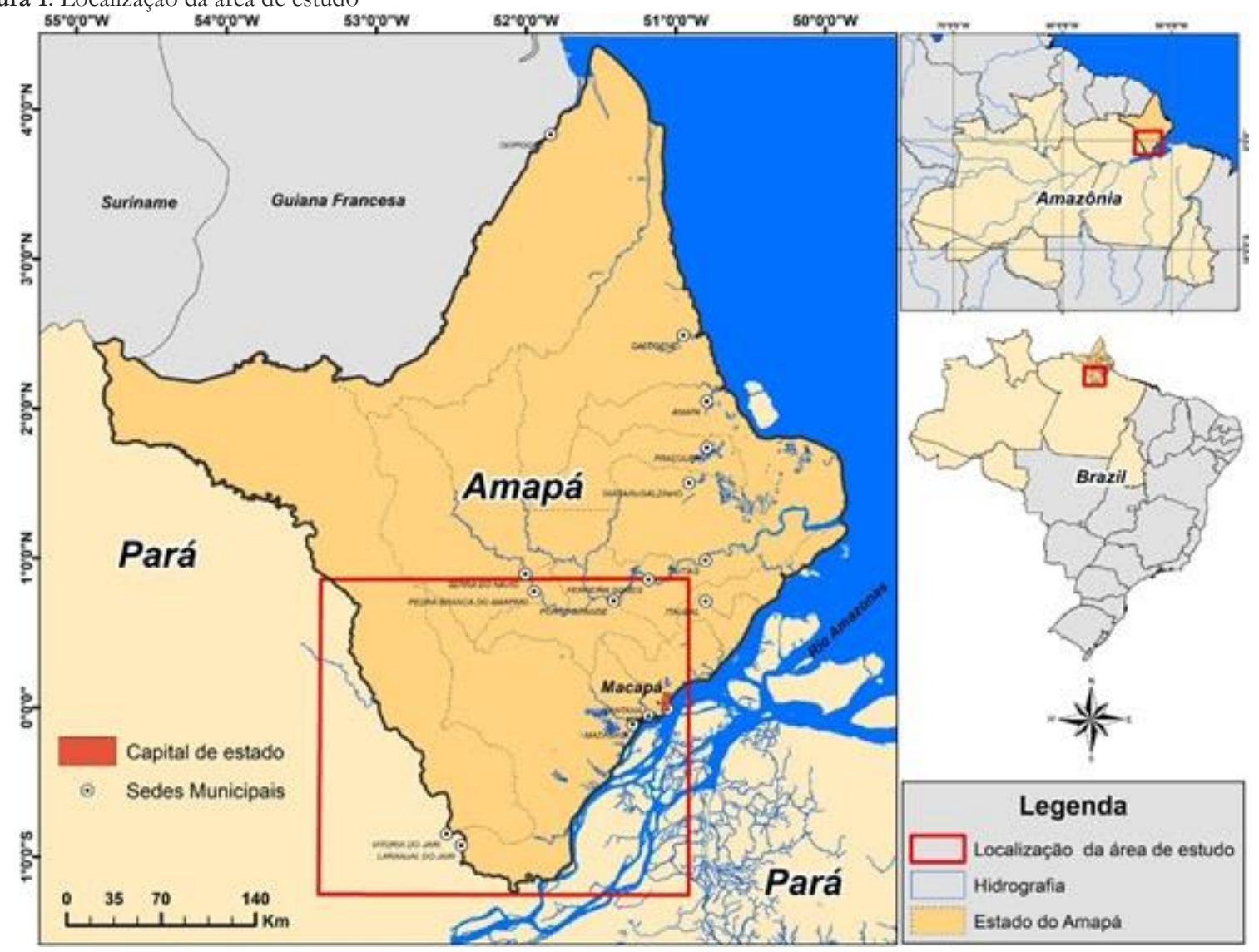

Elaboração: Autor.

O estudo foi realizado diante da necessidade de elaboração de mapas para o diagnóstico das estradas e trilhas de escoamento da produção de castanha do Pará (Bertholletia Excelsa) das unidades de conservação do sul do Amapá. Após uma avaliação visual dos mapas existentes, constatou-se uma incongruência visual entre o mapa territorial do projeto de manejo florestal do Grupo Jari, e os mapas do Projeto de Assentamento Agroextrativista do Rio Maracá (PAE Maracá) e da Reserva de Desenvolvimento Sustentável do Rio Iratapuru (RDS Iratapuru). A partir dessa análise prévia buscou-se verificar se de fato havia sobreposições territoriais, suas extensões e prováveis implicações.

As três unidades territoriais, abrigam comunidades tradicionais no seu interior ou entorno que desenvolvem atividades produtivas rurais. Dentre as atividades mais significativas destacase o extrativismo da castanha da Amazônia, importante tanto por sua capacidade de inclusão produtiva quanto pela conservação de imensas áreas verdes. Os extrativistas, em sua atividade de coleta do ouriço para a extração da amêndoa, também se caracterizam como monitoradores da qualidade dos ambientes florestados. 
A coleta da castanha da Amazônia é uma atividade tradicional que remonta aos primórdios do processo de apropriação espacial da Amazônia pelos europeus. Nas terras entre o norte do estado do Pará e sul do Amapá essa atividade associada a outros tipos de extrativismo vegetal como a extração da borracha, pimentas nativas e retirada de madeira, foi responsável por um ciclo de dinamização da economia que perdurou até meados do século XX. Segundo Lins (1997) o início da apropriação efetiva da região sul do Amapá pela cultura ocidental, data da primeira metade do século XVII, quando no ano de 1623, Bento Maciel Parente, então Governador do Grão Pará, fundou uma casa forte na região do rio Cajari.

A primeira tentativa dos portugueses de manterem a soberania sobre as terras do sul do Amapá foi seguida de muitas outras ações que iriam tentar consolidar o domínio dessas terras diante das constantes investidas de ingleses, franceses e holandeses, que também tinham pretensões de domínio sobre a região. Apesar dos constantes embates, os portugueses conseguiram manter seu domínio, ainda que de forma frágil até meados do século XIX. Entre a segunda metade do século XIX e primeira metade do século XX, os portugueses passaram a dividir com os grupos emergentes da sociedade regional o poder e o domínio sobre as terras amapaenses (LINS, 1997).

Dentre os mais notórios empreendedores das elites regionais, destaca-se o nordestino José Júlio de Andrade. Conhecido como coronel "Zé Julio", esse cearense conseguiu comprar a maior parte das terras do sul do Amapá. Essas propriedades permaneceram sob seu domínio até a primeira metade do século XX, quando então vendeu a um grupo de portugueses (LINS, 1997). Posteriormente as terras de Zé Júlio seriam repassadas para Daniel Ludwig e em seguida ao Grupo Jari, atual detentor de uma área que alega ter 245 mil hectares (RIBEIRO et.al.; 2013).

Avaliando o processo histórico de apropriação da Amazônia, Gonçalves (2005) afirma que de um modo geral essa apropriação sempre se desenvolveu de forma exógena. Essa dinâmica deixou na configuração socioespacial da Amazônia, as marcas indeléveis dos diversos conflitos que nela se processaram e ainda se processam. Os conflitos de hoje são resultantes dos conflitos pretéritos e ainda estão sob a égide de conceitos que por séculos têm norteado a formatação espacial na região.

O conceito de território clássico adotado pelas ciências humanas é pressuposto teórico para o estudo de sobreposição territorial. Os entes territorializadores, só podem ser compreendidos como agentes que definem suas áreas de domínio através de divisas entendidas pelos marcos territoriais físicos presentes nas áreas em questão. De outra forma esses entes se caracterizam como pessoas de natureza jurídica capacitadas a estabelecer acordos objetivando a cessação de eventuais conflitos territoriais (MARTIN, 1998).

O território na abordagem clássica, segundo Martin (1998), pode ser entendido como um ente fisicamente demarcado e política ou juridicamente delimitado. Nessa abordagem, o território pressupõe a existência de um marco físico, que pode ser um rio, igarapé, crista montanhosa, área costeira ou linha seca imaginária. Nesse sentido, o território, pode também ser consolidado fisicamente por marcos que delineiam segmentos de reta considerando determinados ângulos azimutais ou pontos de coordenadas geográficas. Mas o território também pressupõe o limite, ou acordo político/jurídico. Os termos desse acordo são definidos em documento descritivo que pode ser um memorial aprovado e homologado pelas partes envolvidas no processo de disputa territorial. 


\section{METODOLOGIA}

O método de estudo consistiu na consulta, cruzamento e análise espacial em Sistema de Informação Geográfica (SIG) das informações fornecidas nas bases georreferenciadas (vetores) dos territórios analisados. Também foram consultados documentos como o relatório de Descrição do Projeto REDD+ Jari/Amapá e outros com dados e informações territoriais dos entes do estudo. Essas consultas foram, portanto, realizadas em fontes com atuação ou circunscrição relacionada direta ou indiretamente a esses entes territoriais.

Entre as fontes cedentes de bases georreferenciadas destaca-se, o Instituto Nacional de Colonização e Reforma Agrária (INCRA), órgão responsável pelo PAE Maracá. A base georreferenciada da RDS Iratapuru foi cedida pela Secretaria Estadual do Meio Ambiente do Estado do Amapá (SEMA-AP). O Instituto de Estudos e Pesquisas Científicas e Tecnológicas do Amapá (IEPA) e a Conservação Internacional do Brasil (CI do Brasil) cederam as bases georreferenciadas da RESEX Cajari e comunidades.

Como ferramenta auxiliar utilizou-se o sistema de informações geográficas (SIG) ARQGIS 9.3, da empresa ESRI Software. As bases georreferenciadas foram reprojetados para o sistema de coordenadas planas com o Datum WGS 1984. Em seguida essas bases foram inseridas e analisadas no SIG para o cálculo das extensões territoriais sobrepostas e confecção do mapa de sobreposições.

Para o tratamento em SIG utilizou-se o sistema de coordenadas com Datum WGS 1984, já recomendado por Bernardi e Landim (2002) como o mais adequado para a uniformização das informações considerando o uso de diferentes Sistemas de Informações Geográficas (SIG) e a multiplicidade das bases de dados no Brasil. A maioria dessas bases utiliza os Datum SAD 69 (ainda em uso pelo IBGE) e o Córrego Alegre, para tratamento de dados cartográficos no país.

\section{RESULTADOS E DISCUSSÃO}

De acordo com os documentos e bases georreferenciadas analisados o território do Projeto REDD+ Jari/Amapá pertencente ao Grupo Jari, compreenderia um polígono com aproximadamente 245 mil hectares (Figura 2, A+B+C). Esse polígono abrangeria terras dos municípios de Vitória do Jari, Laranjal do Jari e Mazagão, situando-se na porção sul do estado do Amapá. Entretanto, essas informações conflitam com os dados e informações disponíveis sobre a situação territorial dessa região, fornecidos pelos órgãos da administração pública consultados.

Pelo tratamento realizado em SIG, o território do projeto de manejo florestal do Grupo Jari, notadamente em seus limites norte/nordeste estaria sobreposto aos territórios que compreendem terras da RDS Iratapuru e PAE Maracá. A sobreposição territorial total sobre a RDS Iratapuru e o PAE Maracá é de aproximadamente 69 mil hectares (Figura 2, polígono $A+B)$. Subtraindo-se essa extensão territorial sobreposta sobre as duas áreas protegidas, o território total efetivo calculado do projeto de manejo madeireiro do Grupo Jari (e que de fato pertenceria ao Grupo Jari) seria de aproximadamente 176.000 hectares ou $1760 \mathrm{~km}^{2}$ (Figura 2, polígono $\mathrm{C})$. 
Figura 2 : Mapa de sobreposições territoriais nas áreas protegidas do sul do Amapá.

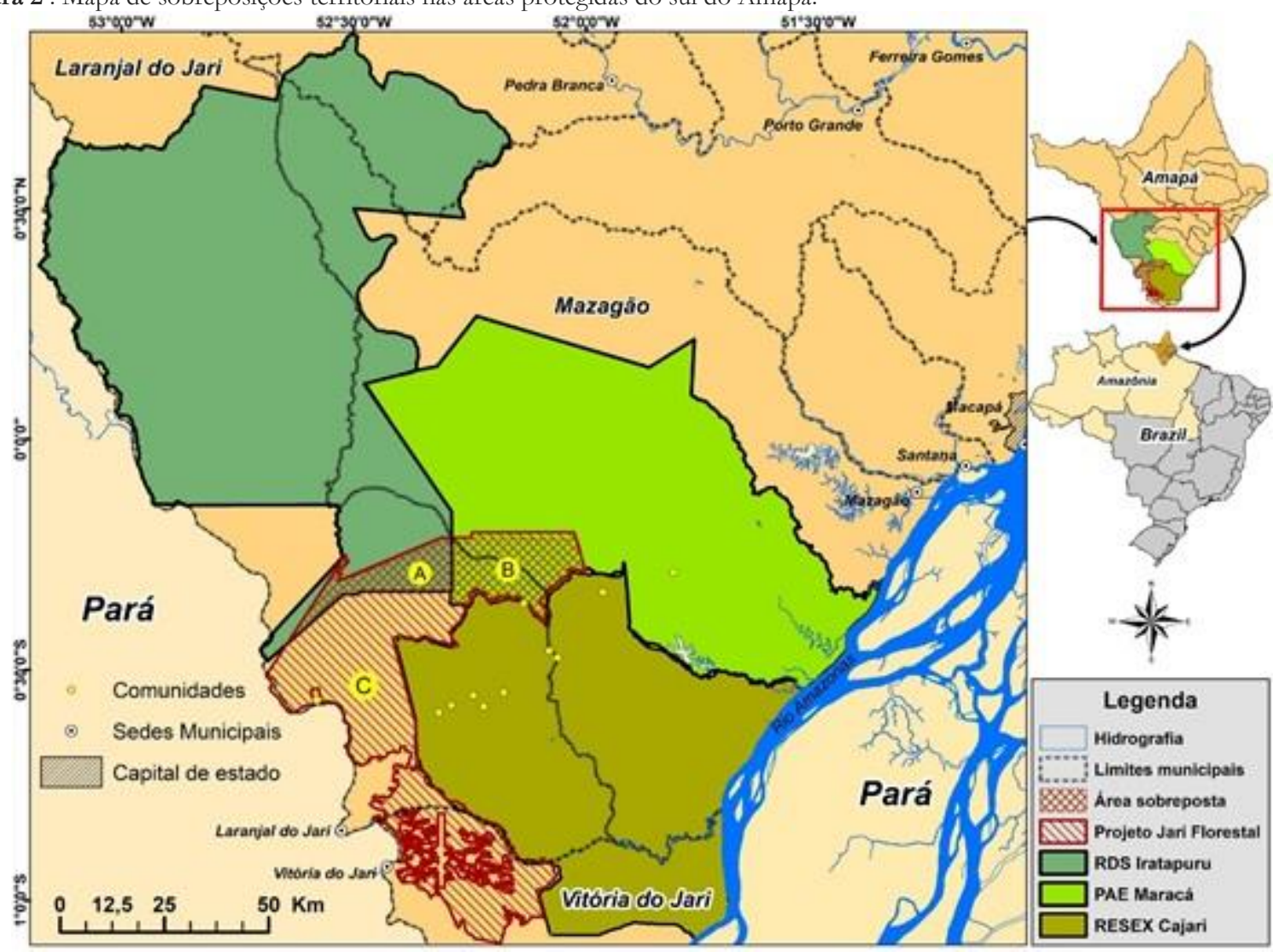

Elaboração: Autor

A RDS Iratapuru foi criada através da Lei Estadual no392 de 11 de dezembro de 1997 sendo uma Unidade de Conservação (UC) de uso sustentável. Essa UC pertence ao sistema de unidades de conservação do Amapá, sendo, portanto, um ente jurídico cujas terras estão sob o domínio direto do Estado do Amapá (AMAPÁ,1997). A extensão territorial total da RDS Iratapuru é de aproximadamente 806.184 hectares. De acordo a análise efetuada, a considerar o mapeamento apresentado por Ribeiro et. al. (2013) as terras situadas na porção sul da RDS Iratapuru, estariam, dentro dos limites territoriais do projeto de manejo do Grupo Jari. Conforme cruzamento dos dados, as terras do projeto e da RDS Iratapuru teriam uma extensão territorial comum (sobreposta) de aproximadamente 27 mil hectares (Figura 2, polígono A).

O PAE Maracá é um Projeto de Assentamento Agroextrativista resultante da unificação dos Paes Maracá I, II e III, criados pelas portarias no 1440,1441 e 1442 do INCRA, de outubro de 1988. O PAE Maracá I tinha uma área total de 75.000 ha, o PAE Maracá II abrangia 22.500 ha e o PAE Maracá III, 266.000 ha. A Portaria no 017, de 28 de abril de 1997 do Ministério Extraordinário de Política Fundiária unificou os três PAEs e redefiniu o número de famílias atendidas no assentamento (BRASIL,1997; MADURO ABREU, 2005). A extensão territorial total do novo PAE Maracá passou a ser de aproximadamente 571.772 hectares, desse total, segundo os dados cruzados com o mapeamento apresentado por Ribeiro et. al. (2013) aproximadamente 42 mil hectares estão sobrepostos a área do projeto de manejo do Grupo Jari (Figura 2, polígono B).

A sobreposição territorial sobre a RDS Iratapuru e o PAE Maracá, se confirmada juridicamente, instigaria a uma readequação dos marcos físicos dos três entes territoriais. Eventual- 
mente seriam necessárias reformulações tanto das atividades de manejo florestal no território do Projeto REDD+ Jari/Amapá do Grupo Jari quanto daquelas atividades rurais desenvolvidas no contexto da RDS Iratapuru e do PAE Maracá. Consequentemente, em função dessa readequação de marcos territoriais, o projeto de manejo florestal do Grupo Jari poderia ficar restrito aos municípios de Laranjal do Jari e Vitória do Jari uma vez que as terras sobrepostas sobre o PAE Maracá, no município de Mazagão, estariam fora de sua circunscrição (Figura 2, polígono B).

\section{CONSIDERAÇÕES FINAIS}

O mapeamento apresentado neste estudo apresenta erros de aproximação. Esses erros decorrem principalmente pela utilização de bases vetoriais de diferentes fontes. Eventualmente, as imagens raster sobre as quais se construíram os vetores utilizados para o estudo podem ser de diferentes fontes, havendo, portanto, a possibilidade de georreferenciamento com pequenas divergências.

Os erros de aproximação, entretanto, não comprometeram sobremaneira os resultados apresentados no estudo. Isso se justifica, uma vez que a análise visual dos contornos são relativamente coincidentes. Ademais as extensões territoriais e os valores de sobreposição em termos reais de hectares são relativamente elevados, 27 mil para a sobreposição sobre a RDS Iratapuru e 42 mil para o PAE Maracá. Esses valores, excedem muito o que se poderia considerar de erro tolerável, algo em torno de algumas dezenas de hectares ou na máxima tolerância até centenas de hectares.

Diante dos resultados da análise apresentada, recomenda-se uma pesquisa reavaliativa, nas fontes originais, dos fatos e informações jurídicas fornecidas para a formulação dos limites e estabelecimento dos marcos físicos das áreas sobrepostas. Os resultados provenientes desta pesquisa reavaliativa que ora se propõe, podem ser fundamentais para evitar futuras possíveis contradições e conflitos de ordem social, jurídica e institucional diante do cenário de sobreposições territoriais apresentado neste estudo.

Ao que tudo indica, o território que o Grupo Jari alega pertencer-lhe na atualidade sofreu várias modificações ao longo do tempo. Essas modificações tiveram origem no processo de aquisição das terras, realizada através de compra direta ou acordos com antigos e mais recentes detentores de propriedade na região sul do Amapá. Para a ratificação desse território somouse o esforço e a atuação dos governos federal e estadual no sentido de consolidar as atividades extravistas mineral e florestal em escala industrial desenvolvidas pelo Grupo Jari. Essas atividades constituem importante fonte de emprego e renda no sul do Amapá e norte do Pará. Não resta dúvida que destarte as sobreposições territoriais existirem, há também a necessidade de coadunar o processo de proteção da floresta e seus serviços com o desenvolvimento socioeconômico regional. Nesse sentido, não há incompatibilidade entre o empreendimento do Grupo Jari e a natureza do uso nas extensões territoriais sobrepostas.

Situados em áreas ainda pouco acessadas, os polígonos de sobreposição territorial não são motivo de conflitos atualmente. Entretando, uma eventual disputa pela posse do território pode ser iminente. Apesar disso, quaisquer que sejam as alegações dos agentes envolvidos, o mais importante nessas áreas sobrepostas é a natureza de sua apropriação, que pode tornar-se elemento dissuasivo de conflitos. Tanto o manejo florestal, proposto pelo Grupo Jari quanto o extrativismo de produtos florestais não madeireiros como o realizado pelas comunidades 
tradicionais envolvidas pressupõe o uso sustentável da floresta.

Os atuais limites territoriais das áreas protegidas no sul do Amapá, foram também estabelecidos em tempos históricos batante distintos. Pela imprecisão dos dados disponíveis, ao que tudo indica, a metodologia utilizada para demarcação da Reserva de Desenvolvimento Sustentável do Rio Iratapuru precisaria de mais estudos de validação com visitas técnicas em campo para ajustes desses dados. De outra maneira, a extensão territorial sobreposta ao PAE Maracá abriga extrativistas deste assentamento e também da RESEX Cajari, fato que corrobora a apropriação histórica desse polígono territorial pelas populações tradicionais.

Em meio às incertezas de ordem jurídica e institucional existe um contexto social que transcende as questões de ordem demarcatória. As populações tradicionais, em especial os extrativistas da castanha da Amazônia, inseridos dentro das extensões territoriais sobrepostas, são muito dependentes dos recursos da biodiversidade para o seu sustento. Ademais, esses extrativistas, também atuam como importantes agentes no processo de conservação ambiental, sendo peças-chave no processo de gestão dessas grandes áreas protegidas no sul do Amapá.

O novo modelo de desenvolvimento socioeconômico intrínseco na proposta de manejo florestal do Grupo Jari coaduna-se com o modelo de apropriação da floresta realizado pelas comunidades locais. Ressalta-se entretanto, que nesse caso a legitimação do direito de propriedade pode conflitar-se com o do direito ao uso. Isso deve-se ao fato de que nas extensões territoriais sobrepostas o direito de propriedade alegado pela Grupo Jari pode legitimar a expropriação do direito ao uso dos recursos florestais pelos extrativistas que alí labutam.

Faz-se necessário ressaltar que o direito de propriedade sobre as extensões territoriais sobrepostas relaciona-se à forma de apropriação, que para as partes envolvidas ocorre de maneira diferenciada. Para os extrativistas, ainda que a apropriação dos recursos da floresta seja importante fonte de renda, esta relaciona-se muito mais à sua subsistência. Para o Grupo Jari a apropriação dos recursos da floresta está estritamente relacionada às trocas comerciais em larga escala. Resta aguardar que num futuro próximo não haja conflitos de interesses. É factível que uma vez que as extensões territoriais sobrepostas, reivindicadas pela iniciativa privada forem sendo apropriadas, possam sobrepor-se ao labor dos extrativistas locais. Isso deve-se ao fato de que cada parcela de manejo florestal supõe intervalos de aproximadamente 30 anos até nova incursão.

\section{REFERÊNCIAS}

AMAPÁ (Estado). Lei no 0392, de 11 de dezembro de 1997. Dispõe sobre a criação da Reserva de Desenvolvimento Sustentável - RDS do Rio Iratapuru, nos Município de Laranjal do Jari, Mazagão e Amapari, no estado do Amapá.

BARRETO Paulo et. al.; tradução de Glaucia Barreto e Tatiana Veríssimo. Pressão humana na floresta amazônica brasileira = Human pressure on the Brasilian Amazon Forest Biome . Belém: WRI; Imazon, 2005.

BERNARDI, J.V.E. \& LANDIM, P.M.B. Aplicação do Sistema de Posicionamento Global (GPS) na coleta de dados. DGA, IGCE, UNESP/Rio Claro, Lab. Geomatemática, Texto Didático 10, 31 pp. 2002. Disponível em http://www.rc.unesp.br/igce/aplicada/textodi.html. Acesso em 22/09/2009. 
BRASIL, Ministério Extraordinário de Políticas Fundiárias. Portaria no 17 de 28 de abril de 1997. Dispõe sobre a criação do Projeto de Assentamento Agroextrativista do Rio MaracáPAE Maracá. Disponível em: https://acervo.socioambiental.org/acervo/area-protegida/projeto-de-assentamento-agroextrativista-maraca-pae-pae. Acesso em 17/07/2019

BRITALDO, Silveira Soares-Filho et.al. Modelling conservation in the Amazon basin. NATURE.Vol 440: March 2006.

FEARNSIDE, Philip M. As Mudanças Climáticas Globais e a Floresta Amazônica in Buckeridge Marcos (ed.), A Biologia e as Mudanças Climáticas Globais no Brasil. Universidade de São Paulo, São Paulo,2008

GONÇALVES, Carlos Walter Porto. Amazônia, Amazônias. 2 ed.- São Paulo: Contexto, 2005.

KOHLHEPP Gerd. Conflitos de interesse no ordenamento territorial da Amazônia brasileira. Estudos Avançados 16 (45), 2002.

LINS, Cristóvão, A Jari e a Amazônia. Rio de Janeiro: DATAFORMA em convênio com a prefeitura Municipal de Almeirim, 1997.

MADURO ABREU, Alexandre. Por uma Gestão Sistêmica e Participativa Local - GSPL: o caso das comunidades do Médio Maracá, AP, 142 p., 297 mm, (UnB-CDS, Mestre, Política e Gestão Ambiental, 2005). Dissertação de Mestrado - Universidade de Brasília. Centro de Desenvolvimento Sustentável.

MARENGO, J. A.; NOBRE, C. A.; CHOU, S. C.; TOMASELLA, J.; SAMPAIO, G.; ALVES, L. M.; OBREGÓN, G. O.; SOARES, W. R.; BETTS, R.; KAY, G. Riscos das mudanças climáticas no Brasil. Análise Conjunta Brasil - Reino Unido Sobre os Impactos das Mudanças Climáticas e do Desmatamento na Amazônia. Brasília: 2011.

MARTIN, André Roberto. Fronteiras e nações. 4ª Ed. São Paulo: Contexto, 1998. - (Repensando a Geografia).

PARKER, C., Mitchell, A., Trivedi, M., Mardas, N. The Little REDD+ Book (2009). RIBEIRO, Plínio, et.al. Projeto REDD+Jari/Amapá, versão 1,4. Biofílica Investimentos Ambientais S/A.2013. 